\title{
Ergonomically Redesigning Paint Spatula Scraper to Reduce Risks Associated to Work-Related Disorders: A Case of Calumpit, Bulacan
}

\author{
Jeremy Laurence Mendoza Bañez, Jhonnel Ignacio Dela Cruz, Rosechel Joy Stacy San Juan, \\ Neil Patrick Mendoza Torres
}

College of Engineering, Bulacan State University, City of Malolos, Philippines

Email address:

jeremylaurence.banez@bulsu.edu.ph (J. L. M. Bañez), jhonneldelacruz.jde@gmail.com (J. I. D. Cruz),

ligaystacy@gmail.com (R. J. S. S. Juan),neilpatrickmtorres@gmail.com (N. P. M. Torres)

\section{To cite this article:}

Jeremy Laurence Mendoza Bañez, Jhonnel Ignacio Dela Cruz, Rosechel Joy Stacy San Juan, Neil Patrick Mendoza Torres. Ergonomically Redesigning Paint Spatula Scraper to Reduce Risks Associated to Work-Related Disorders: A Case of Calumpit, Bulacan. International Journal of Science, Technology and Society. Vol. 7, No. 4, 2019, pp. 61-73. doi: 10.11648/j.ijsts.20190704.12

Received: June 28, 2019; Accepted: August 26, 2019; Published: November 5, 2019

\begin{abstract}
With the increase of human population, the demand for infrastructures, estates and housing also increase. For that reason, construction firms become in-demand and its labor force will tend to rise up. Among those are painters who are incharge in finishing of the structures to make them more aesthetically pleasing. Since their role in construction is significant, they must be given special attention to provide them comfort at work. To provide such comfort, the researcher chose one of their commonly used tools aside from paint brushes and paint rollers, the Paint Spatula Scraper (PSS). The researcher assessed paint spatula scraper by the discomfort it brings to painters in a construction of an apartment in Calumpit, Bulacan using Body Discomfort Chart and Strain Index Chart. The results showed high risks pertaining to the discomfort that was being experienced by the workers that may lead to work-related disorders like Musculoskeletal Disorders (MSDs) and Cumulative Trauma Disorders (CTDs) if the activity will be done repetitively. To resolve the issue, the researcher proposed an ergonomically redesigned paint spatula scraper that may reduce the stated risks associated when using the present type of scraper used by painters. This study will provide an insight for different construction firms and other related firms that use paint spatula scraper or similar tool to it regarding the risks these tools might pose if not properly designed or not properly evaluated when used in the long run.
\end{abstract}

Keywords: Body Discomfort Chart, Construction Firms, Paint Spatula Scraper, Strain Index Chart, Work-Related Disorders

\section{Introduction}

\subsection{Background of the Study}

Ergonomics is the science of work of people who do it and the way it is done. It specifically concerns more of anthropometry and product design. [1] Anthropometry is the branch of the human science that deals with body which includes the consequences of repetitive motion, materials handling, workplace safety, comfort in using portable devices, working postures, and the work environment. Understanding physical characteristics, capabilities, limitations are needed to reduce the physical discomfort.

In production systems, human workers may be at risk for developing manual work, resulting in pain, inability to work, productivity losses and replacement of personnel. [2] Product design means to create a new product to be sold by a business to its customers. A very broad concept, it is essentially the efficient and effective generation and development of ideas through a process that leads to new products. Considering the people, the researchers redesign wherein a product that properly fits for the users.

Home interior plays a vital role in giving the best ambiance and relaxing environment, while considering interior design or interior painting. But, if the paint is applied improperly and in careless manner, it can cause wrinkling, crazing and flaking paints, inter coat peeling, and solvent blistering. Since, it is inevitable, there are methods for 
removing paints: abrasive, thermal and chemical. [3] This study focused on abrasives, such as scraping where it works by raking the damaged areas of paint away and exerting much force is needed.

Construction-related ergonomics is needed to provide users comfort at their work. In abrasive removal of paint, tools provide discomfort and risks that may result to workrelated disorders. More particularly, it relates to such a scraper having semi-flexible characteristics such that the scraper's handle is weightier than the stainless steel of the scraper wherein the painters may have a hard time scraping the paints. [4]

The present designs of some handles of Paint Spatula Scraper (PSS) maybe risky to the painters. Some grip handles are plastics and metals and the discomfort in hand may occur. Also, most of the scrapers nowadays are made up of wood that may accidentally cause finger splints. With the application of Ergonomics, solutions for the problem were discussed. The redesigned scraper will make the end users work more comfortable at their job in order to become efficient and to maximize their work without any injuries and to lessen the body discomfort.

\subsection{Problem Statement}

Based on the survey conducted in construction site, 30 (21 are right-handed and 9 are left-handed) workers who use scrapers for four to eight hours a day often experience body discomfort while doing the task. This may lead to cumulative trauma disorder due to repetitive motion. [5]
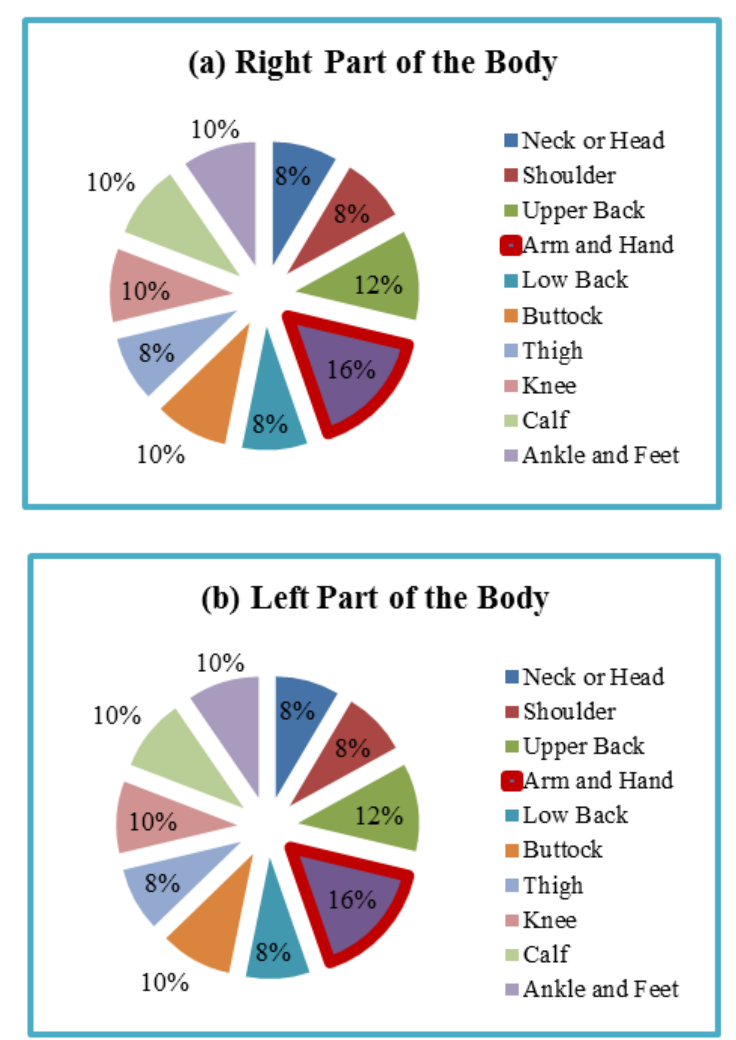

Figure 1. Initial Survey Results Using Body Discomfort Chart on Each Body Part: (a) Right Part; (b) Left Part.

\subsection{Objectives of the Study}

Present work focuses a framework providing the guidelines and principles to the researchers to improve the quality, usability of product (Paint Spatula Scraper) in order to increase the comfort level, reduce the risk of Musculoskeletal Disorder (MSD) due to prolong working in construction site and Cumulative Trauma Disorder (CTD) due to repetitive task.

The objective of the research is to redesign the PSS by considering ergonomic guidelines in order to reduce the risk of body pains such as CTDs and MSDs. Based on this guiding principle, the objective of present work are as follows:

a. To assess the discomfort that occurs on painters while they are scraping

b. To evaluate the data gathered from Body Discomfort Chart and Strain Index Chart

c. To improve the grip handle of Paint Spatula Scraper considering anthropometric measurements particularly in hands of the painters

d. To simulate the newly redesigned Paint Spatula Scraper

e. To determine the comfort work zone considering the newly redesigned Paint Spatula Scraper

\subsection{Rationale of the Study}

Due to numerous constructions of different infrastructures, estates and houses mainly due to increase in population, construction industry becomes in demand. [6] Through that, many construction workers will be hired to suffice the need of the demand. But based on observations especially from small and medium sized construction firms, laborers like that of painters use tools that seem to provide them discomfort. If they repetitively experience such, it may lead to lead high risks of having work-related disorders. [7] One of the tools used by painters is the Paint Spatula Scraper (PSS). It will be assessed if such tool poses certain risks to construction workers and if evaluated to have the risks, the researcher will ergonomically redesign it to reduce the risks associated to it. The end users will benefit to the redesigned paint spatula scraper that might help to the reduction of the body discomfort.

\subsection{Scope and Limitation of the Study}

The study focuses on the construction sites mainly in paint works, design and the other equipment which affect the efficiency and safety of the workers. Data are gathered through observations and questionnaire surveys with the participation of 30 users of Paint Spatula Scrapers from Calumpit, Bulacan renovating an apartment.

The study is limited in the evaluation of the current design and ergonomic redesigning of the Paint Spatula Scraper. Assessing only the posture of the hands of the users and other body parts exposed while scraping were included. 


\subsection{Review of Related Literature}

The purpose of this review of literatures is to assess and understand the application of Ergonomics in the past researches related with scraping task. Also, comfort and discomfort assessment has been a topic of major concern when comparing and evaluating products.

\subsubsection{Manual Task Exertion Risks}

According to the U.S. Department of Labor, handling is defined as: seizing, holding, grasping, turning, or otherwise working with the hand or hands. Fingers are involved only to the extent that they are an extension of the hand, such as to turn a switch or to shift automobile gears. Manual handling of containers may expose workers to physical conditions (e.g., force, awkward postures, and repetitive motions) that can lead to injuries, wasted energy, and wasted time. To avoid these problems, an organization can directly benefit from improving the fit between the demands of work tasks and the capabilities of the workers. Remember that workers' abilities to perform work tasks may vary because of differences in age, physical condition, strength, gender, stature, and other factors. In short, changing the workplace by improving the fit can benefit the workplace by: reducing or preventing injuries; reducing workers' efforts by decreasing forces in lifting, handling, pushing, and pulling materials; reducing risk factors for musculoskeletal disorders (e.g., awkward postures from reaching into containers); increasing productivity, product and service quality, and worker morale; lowering costs by reducing or eliminating production bottlenecks, error rates or rejects, use of medical services because of musculoskeletal disorders, workers' compensation claims, excessive worker turnover, absenteeism, and retraining. [8]

Musculoskeletal disorders (MSDs) are one of the most common work-related ailments. Throughout Europe they affect millions of workers and cost employers billions of euros. Tackling MSDs helps improve the lives of workers, but it also makes good business sense. Musculoskeletal disorders usually affect the back, neck, shoulders and upper limbs, but lower limbs can also be affected. They cover any damage or disorder of the joints or other tissues. Health problems range from minor aches and pains to more serious medical conditions requiring time off or medical treatment. In more chronic cases, they can even lead to disability and the need to give up work. The two main groups of MSDs are back pain/injuries and work-related upper limb disorders (commonly known as 'repetitive strain injuries'). Most workrelated MSDs develop over time. There is usually no single cause of MSDs; various factors often work in combination. Physical causes and organizational risk factors include: handling loads, especially when bending and twisting, repetitive or forceful movements, awkward and static postures, vibration, poor lighting or cold working environments, fast-paced work, and prolonged sitting or standing in the same position. [9]

\subsubsection{Wrist Injury on Workers}

Wrist tendonitis occurs when the tendons in your wrist become inflamed, usually as a result of repetitive motion and/or overuse of the wrist. For this reason, perhaps the most commonly-identified form of wrist tendonitis is a Repetitive Strain Injury (RSI) known as Carpal Tunnel Syndrome. This results over time from sustained periods of activities such as typing, or playing a musical instrument. Chefs, surgeons and some athletes may also experience this because they use their wrists and hands so much in the scope of their jobs. Symptoms of an RSI in the wrist may include decreased dexterity, loss of feeling in the hands, chronic pain, and reduced strength, such as a diminished ability to grasp things. Treatments depend on how severe the condition is. If the symptoms are mild, treatment may consist of simple things, such as a period of rest in which the activity is not performed, physical therapy, massage, use of a wrist splint, and/or anti-inflammatory medication. However, if the condition is more severe and a physician suspects nerve damage, surgery may be necessary to resolve or relieve wrist tendonitis symptoms. Surgery will be followed by a recovery period, of course, and it is important to follow the doctor's instructions. You should also obtain his or her advice about whether you should return to your previous employment -including whether there should be any limitations placed on your job duties -- and what your future prognosis will be. [10]

Wrist injuries may not seem like a big deal at first, but one should know that they can potentially be covered by workers' compensation. According to a 2013 FindLaw.com survey, 20 percent of those injured on the job suffered repetitive motion type injuries -- including wrist injuries like carpal tunnel syndrome. Workers may just accept the pain associated with these injuries as acceptable parts of their jobs, but worker's compensation is typically available. Most wrist injuries fall into a category called repetitive stress injuries (RSIs) or repetitive motion injuries (RMIs), and they are fairly common. Wrist damage may take the form of carpal tunnel syndrome, tendinitis (also spelled tendonitis), or bursitis; the symptoms vary from slight aches and pains to debilitating pain, numbness, and loss of movement. Many of these injuries are aggravated by work activity, making it imperative to not ignore them. Workers suffering from wrist injuries may believe that they are not entitled to workers' compensation because their condition may have existed before starting work. However, most RSI and RMI problems (which cover many common wrist injuries) are covered by workers' compensation if the condition is caused or even aggravated by working conditions. For many employees who are engaged in daily typing or other repetitive motion that involves their wrists, these injuries can easily be aggravated and or triggered by normal working conditions. In either case, when a causal connection can be made between a wrist injury and the work environment, there is a good chance it can be covered by workers' compensation. [11] 


\subsubsection{Importance of Anthropometry in Tool Design}

Anthropometry is the branch of ergonomics that deals with body shape and size. People possess different sizes and there is a need to take these variations into consideration whenever a product or work place is designed for their use. In industry the workstation design normally gives little consideration to the anthropometric measurements of the anticipated user. Designs that are incompatible with normal anthropometric measurements of a workforce could result in undesired incidents. The work performed in an environment that does not focus on ergonomics principles could lead to fatigue and discomfort and also injuries which are known as musculoskeletal disorders (MSDs). An ergonomics approach to the design of an industrial workstation attempts to achieve an appropriate balance between the worker capabilities and work requirements. Anthropometric dimensions for a given population can be generated and arranged in table through statistical methods. The need for such anthropometric databases is becoming increasingly important and grows in parallel with the goal to achieve efficient system designs. [12]

Gjessing, Schoenborn, \& Cohen know the importance of adopting a participatory ergonomic approach to the study of tool design in authentic work situations involving tool users. Ergonomic field observation techniques should be applied to hand tools in order to provide specifications that will guide choices made by designers. It is generally admitted that no tool can in itself be considered as ergonomic. It can only be considered as such if it is properly adapted to all the different uses to which a specific user puts it. Given that work situations are by nature diverse, it is difficult to design a universal tool that is adapted to all possible work situations. Moreover, in certain work situations, it may well be more profitable and efficient, as much in terms of production quality as in terms of reduced risk of MSD, to modify certain parameters of the work situation (the object on which the tool is used or an element in the production process, for instance) than to modify the tool. Consequently, tool design includes the tool itself, as previously defined, but also advice, training, and above all the ability to study the specific details of a given work process. [13]

\subsubsection{Study Related in Redesigning Paint Spatula Scraper}

In building industry, painters suffer from more complaints of the upper extremities than the control group in the construction industry. A few years ago, all Dutch painters used the traditional trapezoid scraper. The main problems in working with the traditional trapezoid paint scraper were frequent extreme postures, high force of the hand, arm, and awkward postures in the back, shoulder, neck and elbow. This proves that the physical work demands related to physically demanding construction trades would be reduced by ergonomic measures and consequently MSDs would be maximized. [14]

According to European and Dutch data from the building industry, painters suffer from more complaints of the upper extremities than the control group in the construction industry. A few years ago, all Dutch painters used the traditional triangular scraper. A study was done regarding the workload in painters including working with the paint scraper. Paint scraping was typified as one of the heaviest tasks by the painters. The main problems in working with the traditional triangular paint scraper were: (1) frequent extreme wrist postures; (2) high forces of the arm, also due to the large moment arm; and (3) awkward postures in the back, shoulder, neck, and elbow. Also, the painters saw blade grinding as inefficiency in the task. [15]

\section{Methodology}

\subsection{Methodological Framework}

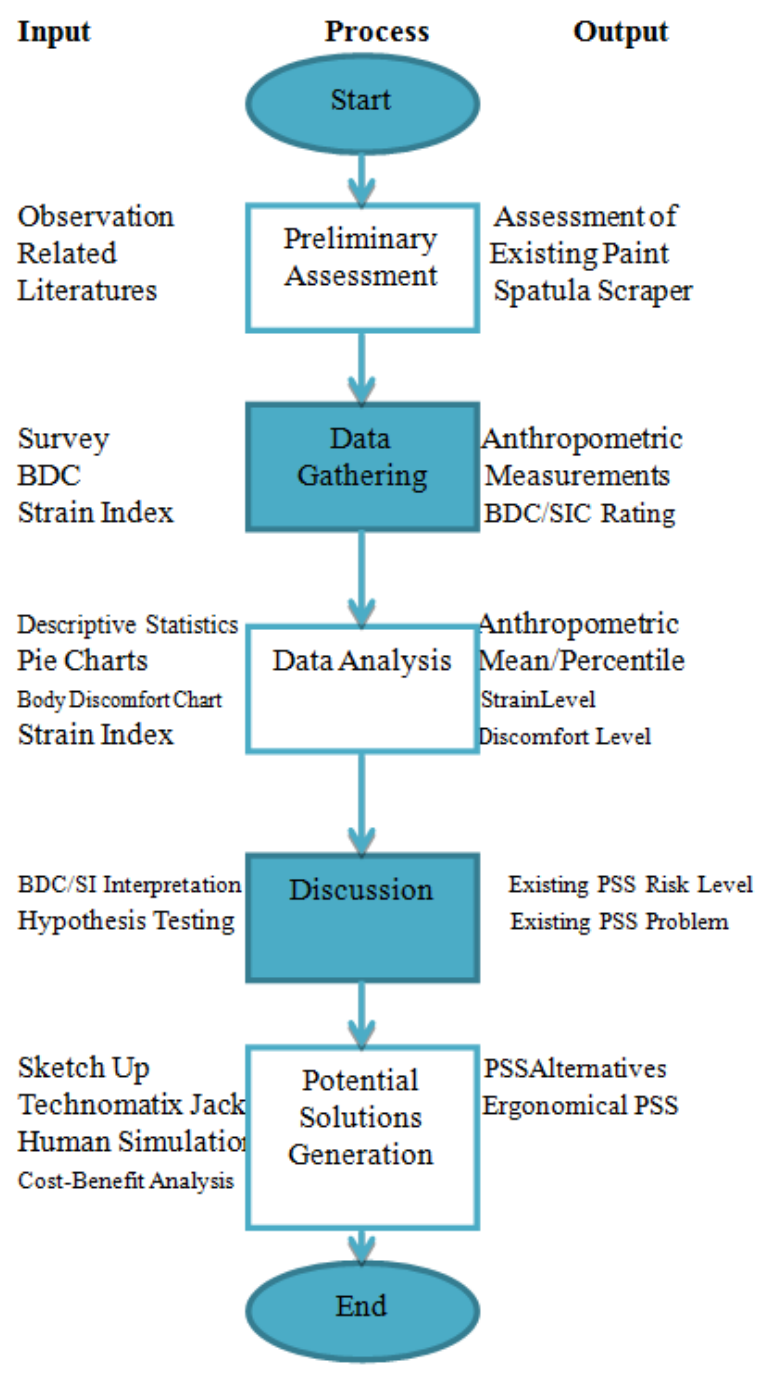

Figure 2. Methodological Framework Flow chart.

\subsection{Subjects in the Study}

The paramount subjects of this study are the end users of paint spatula scraper in the construction industry; 30 construction workers in Calumpit, Bulacan who are exposed to wrinkling, crazing and flaking paints, inter coat peeling, and solvent blistering. (Appendix D) 


\subsection{Anthropometric Data}

Anthropometric data for hand breadth and hand length of workers in accordance to the length and diameter of the proposed paint spatula scraper for the end users is measured through the help of tape measure and ruler.

\subsection{Research Instruments}

\subsubsection{Observation Tools}

The researchers observed the posture of the construction workers while scraping and they assessed the working postures through the use of Body Discomfort Chart (BDC) and Strain Index (SI). After evaluating the result of Body Discomfort Chart and Strain Index, the problem in the arm and hand was distinguished.

It is a form to assess the risk of CTD in the hand/wrist, and the researchers evaluated six task variables (intensity of exertion, duration of exertion, exertions per minute, hand/wrist posture, speed of work, and duration of task per day) by scoring it through a multiplier.

The researchers also used the Body Discomfort Chart to determine the exposed body areas where they feel discomfort. The workers answered the BDC questionnaire during their break time.

\subsubsection{Survey}

Personal information like age and gender of a worker were indicated in the survey questionnaire and also the number of their working hours per day, whether they are right of lefthanded and commonly experienced pain while scraping were included.

\subsection{Data Analysis and Evaluation Tools}

\subsubsection{Statistical Analysis Tool}

The researchers used computer software, Minitab 16 to analyze the data they gathered to prove that the working condition of the workers is at risk.

\subsubsection{Product Design and Simulation Tools}

SketchUp: $3 \mathrm{D}$ is a $3 \mathrm{D}$ modeling computer program for a wide range of drawing application. This is used to draw to proposed design of PSS that will be used for the simulation. Technomatix Jack Human Simulation Software is premium simulation tool for populating the design. Through the use of this software, the researchers will enable to evaluate the proposed designs of the paint spatula scraper without making an actual prototype to be used by humans.

\section{Results and Discussion}

\subsection{Analysis of Results}

The researchers focused their study in evaluating the discomfort that the workers is experiencing while scraping. As shown in Figures 3 and 4, the arm and hand got the highest percentage since these are the most exposed parts of the workers' body while doing the task.

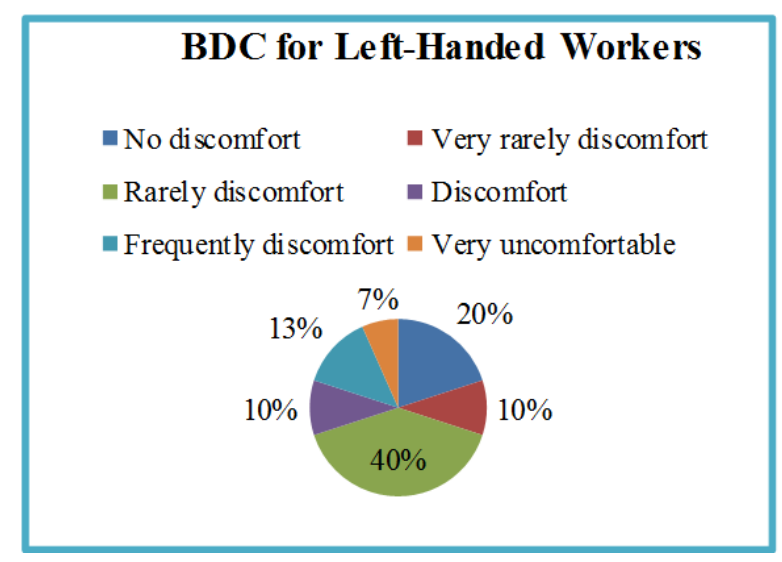

Figure 3. Total BDC Rating for Left-Handed Workers.

Figure 3 shows that twelve (40\%) respondents fell under the rate of rarely discomfort. For the reason that most of the workers are right-handed and as their working time increases, some workers used their hands alternately. The 7\% of the respondents who feels very uncomfortable are the lefthanded workers.

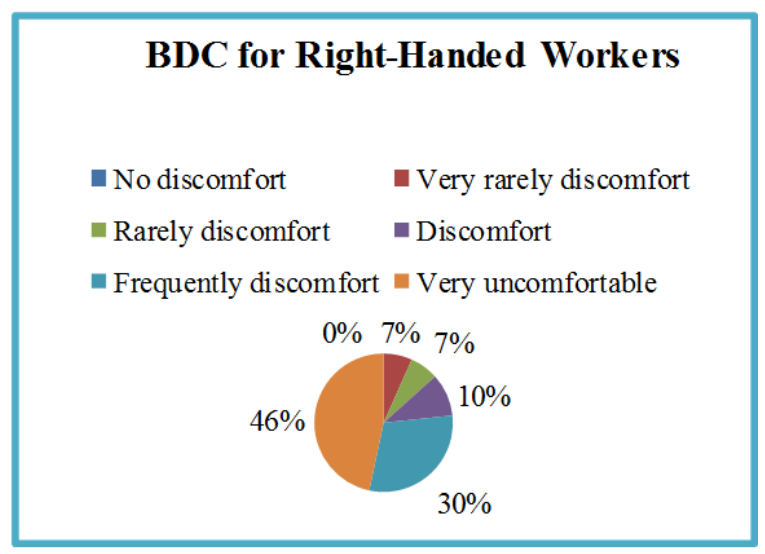

Figure 4. Total BDC Rating for Right-Handed Workers.

Since the majority of the respondents are right- handed, the researchers assessed that the fourteen (46\%) workers experienced very uncomfortable scraping. No worker feels any discomfort as shown in Figure 4 because they also used their hands alternately.

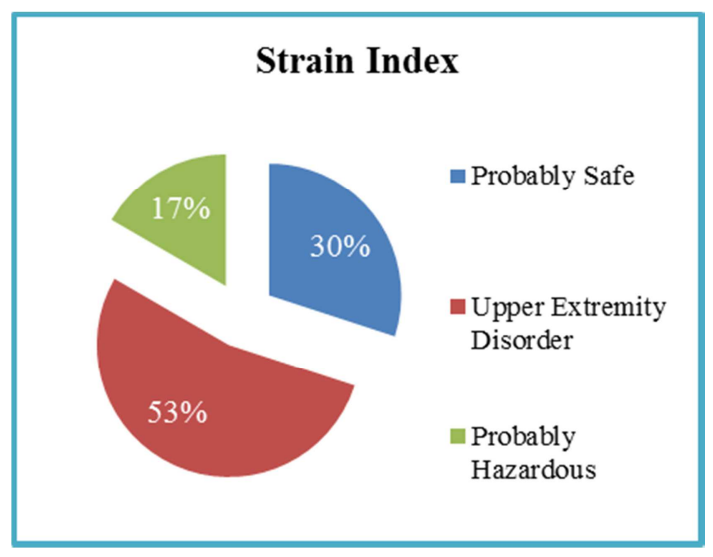

Figure 5. Total Strain Index Rating. 
Strain Index (SI) is used to assess the risk of repetitive task connected with upper extremities (hand, wrist and elbow). If the range of the SI for each worker is not less than three but no more than seven, it will fell to the upper extremity disorders bracket. The job is probably safe if the SI is less than or equal to three while if the SI is greater than or equal to seven, the job is probably hazardous. In Figure 5, sixteen (53\%) workers' task may place individual at increased risk for distal upper extremity disorders. This may due to the posture of wrist that affects the efficiency of their work.

\subsection{Assessment of Present Design of Paint Spatula Scraper}

\subsubsection{Assessment of Wooden Handle PSS}

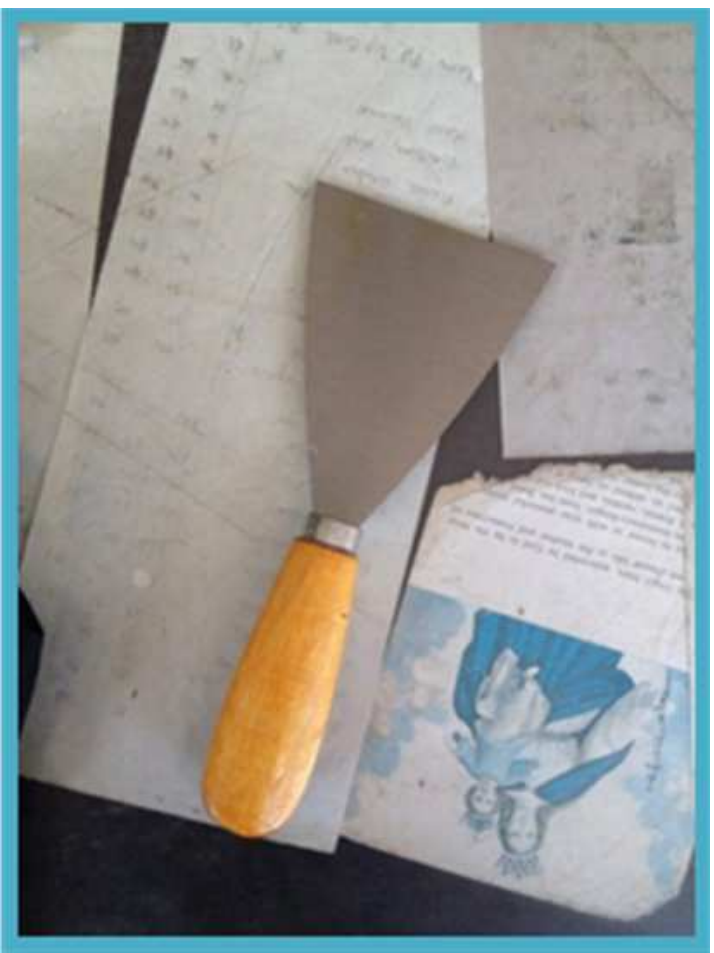

Figure 6. Paint Spatula Scraper with Wooden Handle.

Table 1. Advantages and Disadvantages of Wooden Handle PSS.

\begin{tabular}{|c|c|}
\hline ADVANTAGES & DISADVANTAGES \\
\hline $\begin{array}{l}\text { a. Good quality wood handle } \\
\text { - can be durable and } \\
\text { attractive } \\
\text { b. Wooden handle also adds } \\
\text { a lot beauty to a scraper } \\
\text { c. Wooden handle is simple } \\
\text { to shape than any other } \\
\text { metal grip handle }\end{array}$ & $\begin{array}{l}\text { a. Inappropriate grip size - the optimal } \\
\text { size for a power grip is roughly that } \\
\text { which permits the thumb and the } \\
\text { forefinger to overlap slightly; most } \\
\text { of the wooden scrapers are with } \\
\text { smaller grips so therefore, more } \\
\text { exertion is needed to accomplish the } \\
\text { same work }\end{array}$ \\
\hline $\begin{array}{l}\text { d. Lots of variety unlike the } \\
\text { other grip handles mostly } \\
\text { like plastics and metals } \\
\text { handles making it the }\end{array}$ & $\begin{array}{l}\text { b. Slippery grip - wooden scrapers } \\
\text { have slippery grip that might cause } \\
\text { the user to lose the handle and slip } \\
\text { out of it }\end{array}$ \\
\hline $\begin{array}{l}\text { most common type of } \\
\text { scraper. } \\
\text { e. Wooden handle is } \\
\text { affordable }\end{array}$ & $\begin{array}{l}\text { c. Sensitive to moisture and heat - } \\
\text { regular maintenance and cleaning is } \\
\text { mandatory for the wooden scraper } \\
\text { to stay durable }\end{array}$ \\
\hline
\end{tabular}

\subsubsection{Assessment of Plastic Grip Handle PSS}

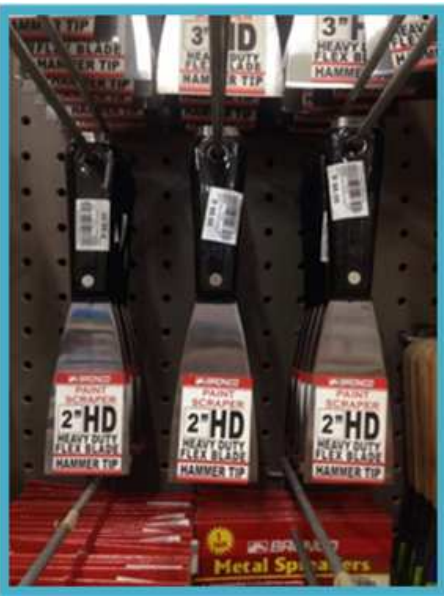

Figure 7. Paint Spatula Scraper with Plastic Grip Handle.

Table 2. Advantages and Disadvantages of Plastic Grip Handle PSS

\begin{tabular}{lll}
\hline ADVANTAGES & DISADVANTAGES \\
\hline $\begin{array}{ll}\text { a. Plastic grip handle scrapers } \\
\text { are light weight than any } \\
\text { other handles available in the } \\
\text { market }\end{array}$ & a. & $\begin{array}{l}\text { Plastic handle scrapers lack } \\
\text { longevity }\end{array}$ \\
$\begin{array}{ll}\text { Known for its strength and } \\
\text { durability so it does not } \\
\text { break when it is dropped or } \\
\text { handled roughly }\end{array}$ & $\begin{array}{l}\text { Not sturdy and cannot predict } \\
\text { how it can withstand heavy } \\
\text { weight and pressure making it } \\
\text { unsafe }\end{array}$ \\
& c. $\begin{array}{l}\text { More expensive than low quality } \\
\text { wooden scrapers } \\
\text { There is a possibility to slip } \\
\text { because of the palsied hands }\end{array}$ \\
\hline
\end{tabular}

\subsubsection{Assessment of Rubberized Handle PSS}

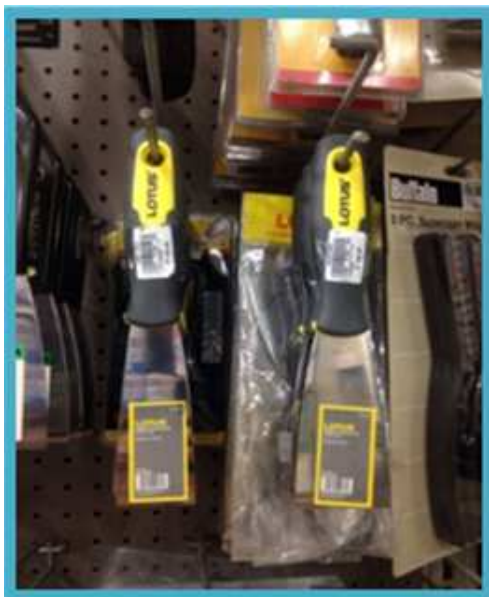

Figure 8. Paint Spatula Scraper with Rubberized Handle.

Table 3. Advantages and Disadvantages of Rubberized Handle PSS.

\begin{tabular}{lll}
\hline ADVANTAGES & DISADVANTAGES \\
\hline a. $\begin{array}{l}\text { Rubberized handle scrapers are } \\
\text { nice to touch and offers a }\end{array}$ & a. & $\begin{array}{l}\text { Rubberized handle scraper is } \\
\text { heavier than plastic and }\end{array}$ \\
$\begin{array}{ll}\text { warmer feel than plastic scrapers } \\
\text { b. Helps to reduce vibration, } \\
\text { enabling a more comfortable and } \\
\text { secure grip }\end{array}$ & b. $\begin{array}{l}\text { Mooden handle scraper } \\
\text { three typen of scrapers }\end{array}$ \\
$\begin{array}{ll}\text { Can help avoid slipping due to } \\
\text { sweat }\end{array}$ & c. & Requires more exertion force \\
\hline
\end{tabular}




\subsection{Hypothesis Testing}

The results of Minitab 16 show that the BDC rating for right and left hand have a significant effect when scraping. The body segments that were used were only the right hand and left hand because they were both on the high risk based on the Figure 1 These results prove that the discomfort is present on both hands of workers while doing their specific task.

Table 4. Test of Hypothesis for BDC Rating for Left and Right Hand.

\begin{tabular}{llll}
\hline Body Segment & Hypothesis & P-value & Interpretation \\
\hline \multirow{2}{*}{ Right Hand } & $\mathrm{H}_{0}: \mu=0$, There is no discomfort & 0.000 & Accept $\mathrm{H}_{1}$, Reject $\mathrm{H}_{0:}$ There is a discomfort \\
& $\mathrm{H}_{1}: \mu>0$, There is a discomfort & & \\
Left Hand & $\mathrm{H}_{0}: \mu=0$, There is no discomfort \\
$\mathrm{H}_{1}: \mu>0$, There is a discomfort & 0.000 & Accept $\mathrm{H}_{1,}$ Reject $\mathrm{H}_{0}$; There is a discomfort \\
\hline
\end{tabular}

\section{Recommendation}

\subsection{Alternatives}

Alternative 1: Using Mild Steel Tube and Non-slip Soft Foam for the Grip handle of Paint Spatula Scraper

Table 5. Anthropometric Data for Alternative 1.

\begin{tabular}{ll}
\hline Hand Length $(\mathbf{c m})$ & Hand Breadth $(\mathbf{c m})$ \\
\hline Mean $=20.0433$ & Mean $=9.3267$ \\
St.Dev. $=0.8468$ & St.Dev. $=0.6843$ \\
$95^{\text {th }}$ Percentile $=21.4405$ & $95^{\text {th }}$ Percentile $=10.4558$ \\
$5^{\text {th }}$ Percentile $=18.6461$ & $5^{\text {th }}$ Percentile $=8.1976$ \\
\hline
\end{tabular}

The researchers used the data gathered from the anthropometric measures of the hands of the users of scrapers (Appendix A); they used it as the basis for the dimensions for their proposed design of the two PSS. The $95^{\text {th }}$ percentile was used. The formula $C=\pi D$ was also used to get the diameter of the inner grip. The outer grip was assumed by the researchers to be $4 \mathrm{~cm}$.

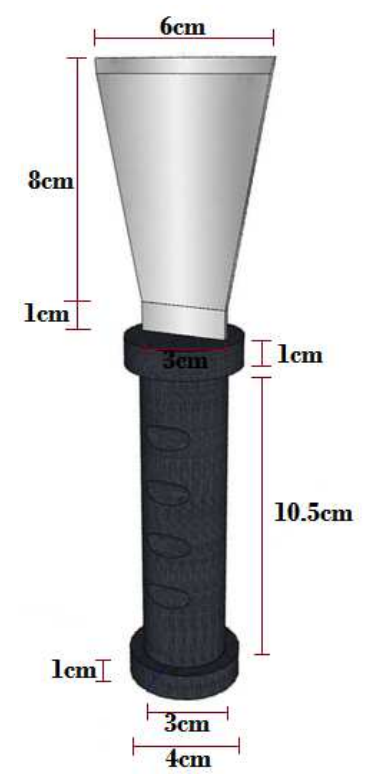

Figure 9. Proposed Paint Scraper Spatula for Alternative 1.

Table 6. Materials Used for Alternative 1.

\begin{tabular}{llll}
\hline Parts of the Scraper & Materials Used & Measurement & Materials Brief Description \\
\hline Blade & Stainless blade & $\begin{array}{l}8 \mathrm{~cm} \times 6 \mathrm{~cm} \\
\text { Blade thickness }=1 \mathrm{~mm}\end{array}$ & $\begin{array}{l}\text { Does not readily corrode, rust or stain } \\
\text { with water as ordinary steel does } \\
\text { Steel tube containing a small percentage } \\
\text { of carbon, strong and tough but not } \\
\text { readily tempered }\end{array}$ \\
Inner Grip & Mild steel tube & $\begin{array}{l}\mathrm{D}=2 \mathrm{~cm} \\
\text { Tube thickness }=1 \mathrm{~mm}\end{array}$ & $\begin{array}{l}\text { Decrease the amount of high frequency } \\
\text { vibration and shock transmitted to the } \\
\text { hands }\end{array}$ \\
Suter Grip & $\begin{array}{l}\text { Non-slip soft foam (finger- } \\
\text { styled) }\end{array}$ & $\begin{array}{l}\mathrm{D}=1 \mathrm{~cm} \\
\text { Foam thickness }=5 \mathrm{~mm} \\
\text { carbon, strong and tough but not readily } \\
\text { tempered }\end{array}$ \\
\hline
\end{tabular}

Table 7. Advantages and Disadvantages of Materials Used in Alternative 1.

\begin{tabular}{|c|c|c|}
\hline Materials Used & Advantages & Disadvantages \\
\hline Stainless Blade & $\begin{array}{l}\text { a. Rustproof } \\
\text { b. Lasts more than other normal scraper blade } \\
\text { c. Strong and durable }\end{array}$ & Slightly inexpensive than the normal blades \\
\hline Mild Steel Tube & $\begin{array}{l}\text { a. Strong and tough } \\
\text { b. Affordable behind in its carbon content } \\
\text { c. Easier to form and to shape } \\
\text { d. Can be welded }\end{array}$ & Low tensile strength \\
\hline
\end{tabular}




\begin{tabular}{lll}
\hline Materials Used & Advantages & Disadvantages \\
\hline & a. Strong and tough & \\
Mild Steel & b. Affordable behind in its carbon content & Low tensile strength \\
& c. Easier to form and to shape & \\
\hline
\end{tabular}

Alternative 2: Using D-Grip and Non-slip Soft Foam for the Grip Handle of Paint Spatula Scraper

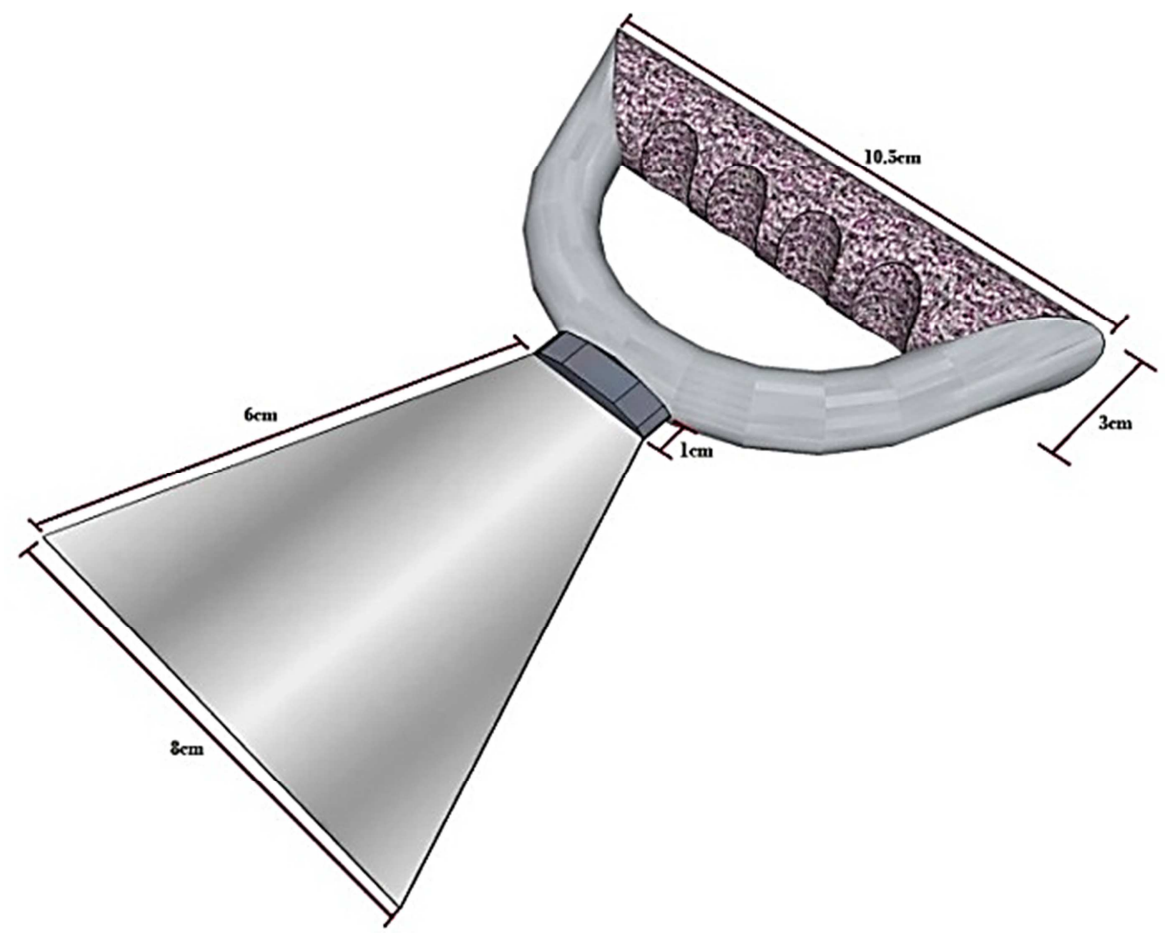

Figure 10. Proposed Paint Scraper Spatula for Alternative 2.

Table 8. Anthropometric Data for Alternative 2.

\begin{tabular}{ll}
\hline Hand Length $(\mathbf{c m})$ & Hand Breadth $(\mathbf{c m})$ \\
\hline Mean $=20.0433$ & Mean $=9.3267$ \\
St.Dev. $=0.8468$ & St.Dev. $=0.6843$ \\
$95^{\text {th }}$ Percentile $=21.4405$ & $95^{\text {th }}$ Percentile $=10.4558$ \\
$5^{\text {th }}$ Percentile $=18.6461$ & $5^{\text {th }}$ Percentile $=8.1976$ \\
\hline
\end{tabular}

anthropometric measures of the hands of the users of scrapers (Appendix A, Table 13); they used it as the basis for the dimensions for their proposed design of the two PSS. The 95th percentile was used (Appendix B, Table 14). The formula $\mathrm{C}=\pi \mathrm{D}$ was also used to get the diameter of the grip.

The researchers used the data gathered from the

Table 9. Materials Used for Alternative 2.

\begin{tabular}{llll}
\hline Parts of the Scraper & Materials Used & Measurement & Materials Brief Description \\
\hline Blade & Stainless Steel Blade & $\begin{array}{l}6 \mathrm{~cm} \times 8 \mathrm{~cm} \\
\text { Blade thickness }=1 \mathrm{~mm}\end{array}$ & $\begin{array}{l}\text { Does not readily corrode, rust or stain with water as ordinary } \\
\text { steel does }\end{array}$ \\
D-Grip & Plastic & $\begin{array}{l}\mathrm{D}=2 \mathrm{~cm} \\
\text { Tube thickness }=1 \mathrm{~mm}\end{array}$ & $\begin{array}{l}\text { D-Grip mounts midway which gives lifting leverage to the } \\
\text { forward hand }\end{array}$ \\
Grip Handle & Non-slip Soft Foam & $\begin{array}{l}\mathrm{D}=1 \mathrm{~cm} \\
\text { Foam thickness }=5 \mathrm{~mm}\end{array}$ & $\begin{array}{l}\text { Decreases the amount of high frequency vibration and shock } \\
\text { transmitted to the hands }\end{array}$ \\
\hline
\end{tabular}

Table 10. Advantages and Disadvantages of Materials Used in Alternative 2.

\begin{tabular}{lll}
\hline Materials Used & Advantages & Disadvantages \\
\hline \multirow{3}{*}{ Stainless Steel Blade } & a. Rustproof & Slightly inexpensive than the normal blades \\
& b. Lasts more than other normal scraper blade & \\
Plastic & c. Strong and durable & Cost of plastic \\
& Strong and durable lightweight material & \\
Non-slip Soft Foam (Finger- & a. Conform to workers' hands making it more ergonomic & b. Whether hot or cold, foam tubes insulate \\
Styled) & c. Comfortable handle grips & Flakes away quite easily after scraping \\
& d. Eliminates blisters & \\
\hline
\end{tabular}




\subsection{Comparison of Alternatives}

\subsubsection{Alternative Simulation}

Alternative 1: Using Mild Steel Tube and Non-slip Soft

Foam for the Grip Handle of Paint Spatula Scraper
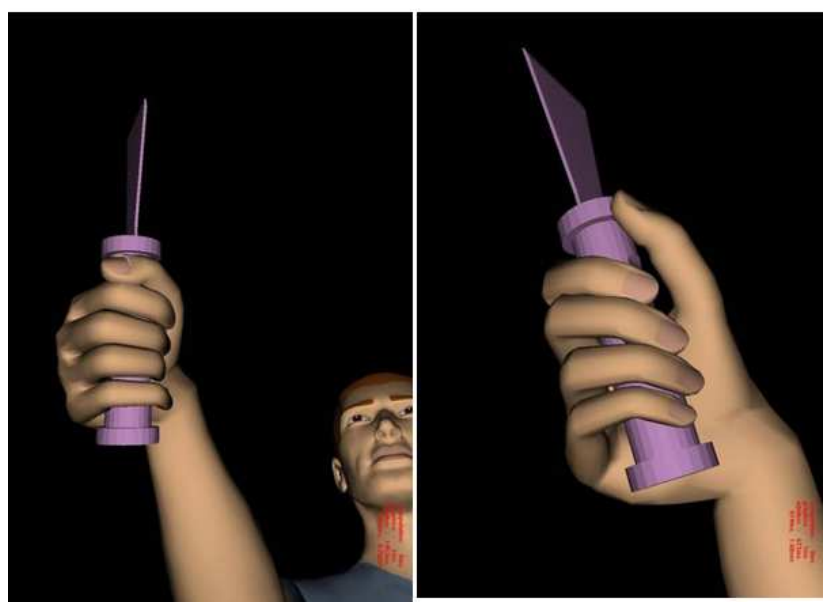

Figure 11. Simulated Wrist and Hand Postures Using Alternative 1.

Alternative 2: Using D-Grip and Non-slip Soft Foam for the Grip Handle of Paint Spatula Scraper
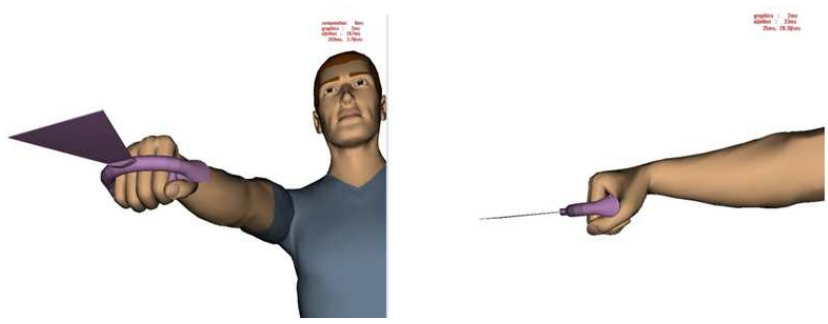

Figure 12. Simulated Wrist and Hand Postures Using Alternative 2.

\subsubsection{Cost Analysis}

Alternative 1: Using Mild Steel Tube and Non-slip Soft Foam for the Grip Handle of Paint Spatula Scraper

Table 11. Cost Comparison between Present PSS and Alternative 1.

\begin{tabular}{lll}
\hline $\begin{array}{l}\text { Part of Scraper } \\
\text { (Redesigned) }\end{array}$ & Present Design of PSS & $\begin{array}{l}\text { Proposed Design of } \\
\text { PSS }\end{array}$ \\
\hline Blade & & P35.00 (welded) \\
Inner Grip & $\mathrm{P} 30.00-\mathrm{P} 180.00$ & $\mathrm{P} 16.00$ \\
Outer Grip & & $\begin{array}{l}\mathrm{P} 40.00 \\
\text { Fingers Supporter }\end{array}$ \\
Total Cost & $\mathrm{P} 30.00-\mathrm{P} 180.00$ & $\mathrm{P} 50.00$ (welded) \\
\hline
\end{tabular}

Alternative 2: Using D-Grip and Non-slip Soft Foam for the Grip Handle of Paint Spatula Scraper

Table 12. Cost Comparison between Present PSS and Alternative 2.

\begin{tabular}{lll}
\hline $\begin{array}{l}\text { Part of Scraper } \\
\text { (Redesigned) }\end{array}$ & Present Design of PSS & $\begin{array}{l}\text { Proposed Design of } \\
\text { PSS }\end{array}$ \\
\hline Blade & & P35.00 (welded) \\
D-Grip & P30.00 - P180.00 & P 80.00 \\
Grip handle & & P40.00 \\
Total Cost & P30.00 - P180.00 & P155.00 (estimated) \\
\hline
\end{tabular}

\subsection{Researchers' Recommendation to the End-Users}

The researchers recommend Alternative 1 because on Alternative 2 (Figure 12) which is the simulated wrist and hand postures, the wrist is strengthened but the trade-off is that the workers will have a hard time scraping because there is no force from the thumb. In scraping process, the thumb is most important, the exertion of force is from it. Perhaps, the workers still need to bend their wrist in order for them to scrape but in Alternative 1 but the CTDs and MSDs will be reduced since the handle is made up of soft grip foam that will make the workers more comfortable.

\section{Conclusion}

After gathering all the data needed, the researcher assessed the discomfort that occurs on painters while they are scraping, and by evaluating the results using Body Discomfort Chart and Strain Index Chart, the researcher found out that the comfort they are experiencing poses risks that might lead to work-related disorders. He concludes that redesigning of the paint spatula scraper (PSS) through the Principles of Ergonomics can reduce the risk of cumulative trauma disorders (CTDs) and musculoskeletal disorders among the painters (MSDs) that were evaluated through the simulation software.

The posture of the worker when scraping contributes in acquiring risk factors when doing the task. The proper design, the dimensions in particular, which will fit the user's anthropometry, is necessary in redesigning to achieve improvement. For scraping, the researcher was able to conclude that using non-slip soft foam for paint spatula scraper handle will minimize discomfort in gripping the said tool. Therefore, the body discomfort might be reduced because in the newly redesigned spatula scraper, the users do not need to exert more force and the users can scrape more comfortably since the grip handle is now ergonomically redesigned.

\section{Areas for Future Work}

The researchers suggest that the area for future studies is to gain more feedbacks from different construction sites on how the redesigned scraper is working to be more accurate in the size of the proposed design of the scraper. And so, it would be enough to justify the study for recommendation. Also, the researchers suggest that the area for future studies is to focus on how to improve more the extended handle and also in blade part because the researcher focused its study in the grip handle.

\section{Acknowledgements}

We would like to express our sincere gratitude to Engr. Hazel Caparas for her support to finish this study. Her expertise in the field and for her patience, motivation, 
enthusiasm, and immense knowledge are much appreciated. Her guidance helped us a lot with the research and writing of this study.

Also, we would like thank Dr. Cecilia Navasero-Gascon, our University President, Dr. Cecilia Geronimo, our university's Vice-President for Research, Extension, and Training, Ms. Jeninna Tongol, the Director of Bulacan State University's Research Office for their unwavering support to submit this study in related conferences provided with fund support by Bulacan State University.

In addition, we would like to thank Engr. Marianne Calayag, our department chair, and other Bulacan State University's IE faculty members namely Engr. Ivy Mar Ramos, Engr. Juan Tecson, Engr. Dyan Rodriguez, Arch. Jeana Venturina, Engr. John Mark Nanip, and Engr. Raph John Miranda for their moral support in this endeavor of pursuing this kind of study to be presented in conferences and to be published on journals.

\section{Appendix}

\section{Appendix A. Anthropometric Measure for the Hand Breadth and Length}

Table 13. Actual Hand Length and Hand Breadth of the Workers $(n=30)$.

\begin{tabular}{|c|c|c|}
\hline Painter & Hand Length (cm) & Hand Breadth $(\mathrm{cm})$ \\
\hline 1 & 19 & 9.2 \\
\hline 2 & 19.2 & 9 \\
\hline 3 & 19.8 & 10 \\
\hline 4 & 21.6 & 10 \\
\hline 5 & 19.3 & 10 \\
\hline 6 & 21.8 & 9.5 \\
\hline 7 & 19.7 & 10 \\
\hline 8 & 20.2 & 9.5 \\
\hline 9 & 19.4 & 8.5 \\
\hline 10 & 19.8 & 10 \\
\hline 11 & 21.3 & 10 \\
\hline 12 & 20.6 & 9.8 \\
\hline 13 & 19.2 & 9 \\
\hline 14 & 18.8 & 8.8 \\
\hline 15 & 20.6 & 9.2 \\
\hline 16 & 20.3 & 10 \\
\hline 17 & 20 & 8.9 \\
\hline 18 & 21.3 & 10.4 \\
\hline 19 & 19.5 & 8.7 \\
\hline 20 & 20.6 & 9.2 \\
\hline 21 & 20.5 & 9 \\
\hline 22 & 21 & 9.3 \\
\hline 23 & 19.4 & 10.2 \\
\hline 24 & 20 & 9.8 \\
\hline 25 & 20.7 & 10.1 \\
\hline 26 & 18.8 & 8 \\
\hline 27 & 20.5 & 8.3 \\
\hline 28 & 20.2 & 9 \\
\hline 29 & 19.2 & 8.3 \\
\hline \multirow[t]{5}{*}{30} & 19 & 8.1 \\
\hline & Mean $=20.0433$ & Mean $=9.3267$ \\
\hline & St.Dev. $=0.8468$ & St.Dev. $=0.6843$ \\
\hline & $95^{\text {th }}$ Percentile $=21.44$ & $95^{\text {th }}$ Percentile $=10.46$ \\
\hline & $5^{\text {th }}$ Percentile $=18.65$ & $5^{\text {th }}$ Percentile $=8.20$ \\
\hline
\end{tabular}

Appendix B. Formulas in Summarizing Anthropometric Measures

Table 14. Formulas for $5^{\text {th }}$ and $95^{\text {th }}$ Percentiles.

\begin{tabular}{ll}
\hline 95 $^{\text {th }}$ percentile: & $\mathbf{5}^{\text {th }}$ percentile: \\
\hline $\mathrm{P}=\mathrm{m}+k \mathrm{SD}$ & $\mathrm{P}=\mathrm{m}-k \mathrm{SD}$ \\
$\mathrm{k}=1.65$ & $\mathrm{k}=1.65$ \\
\hline
\end{tabular}




\section{Appendix C. Observation Tools}

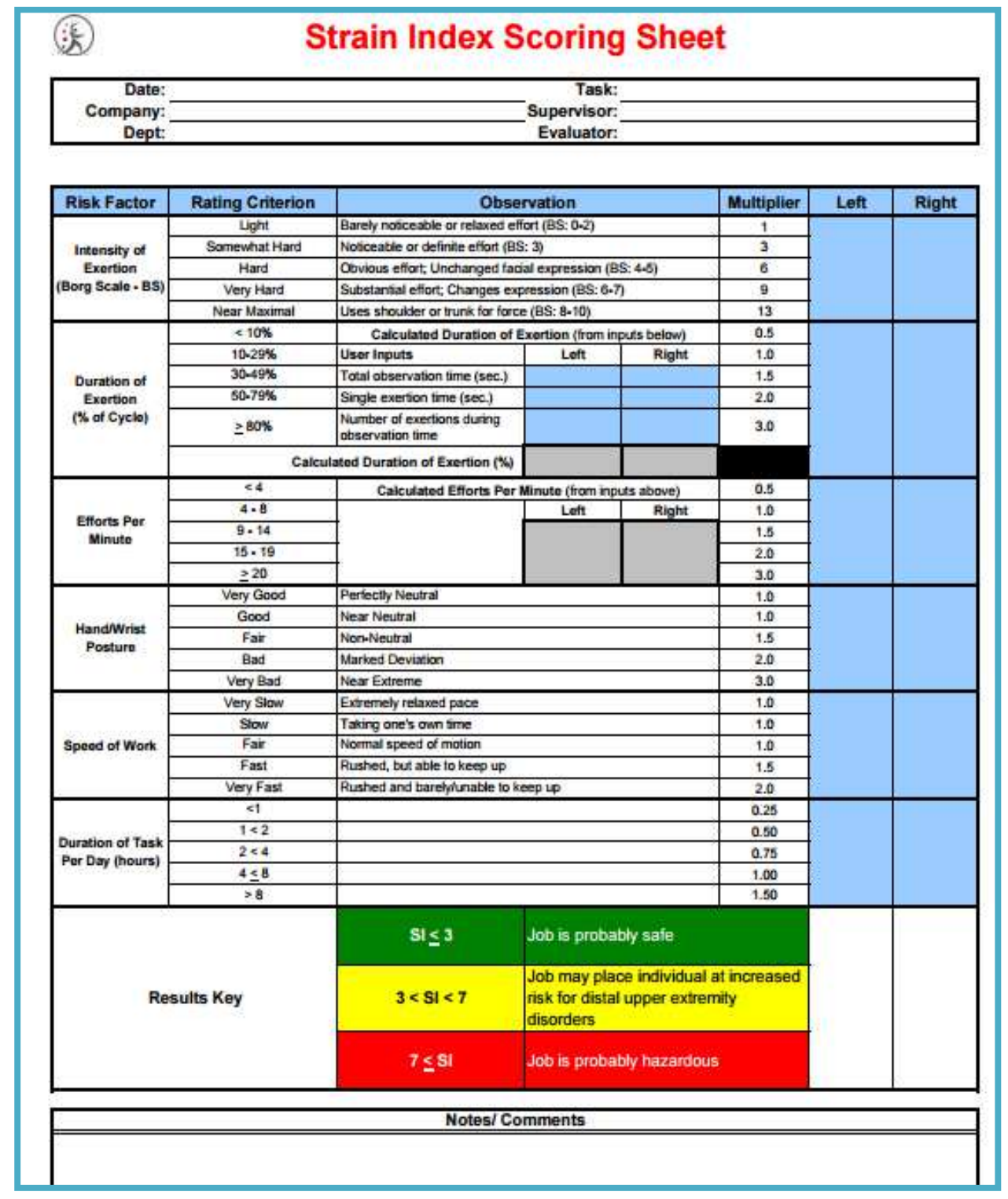

Figure 13. Strain Index Scoring Sheet.

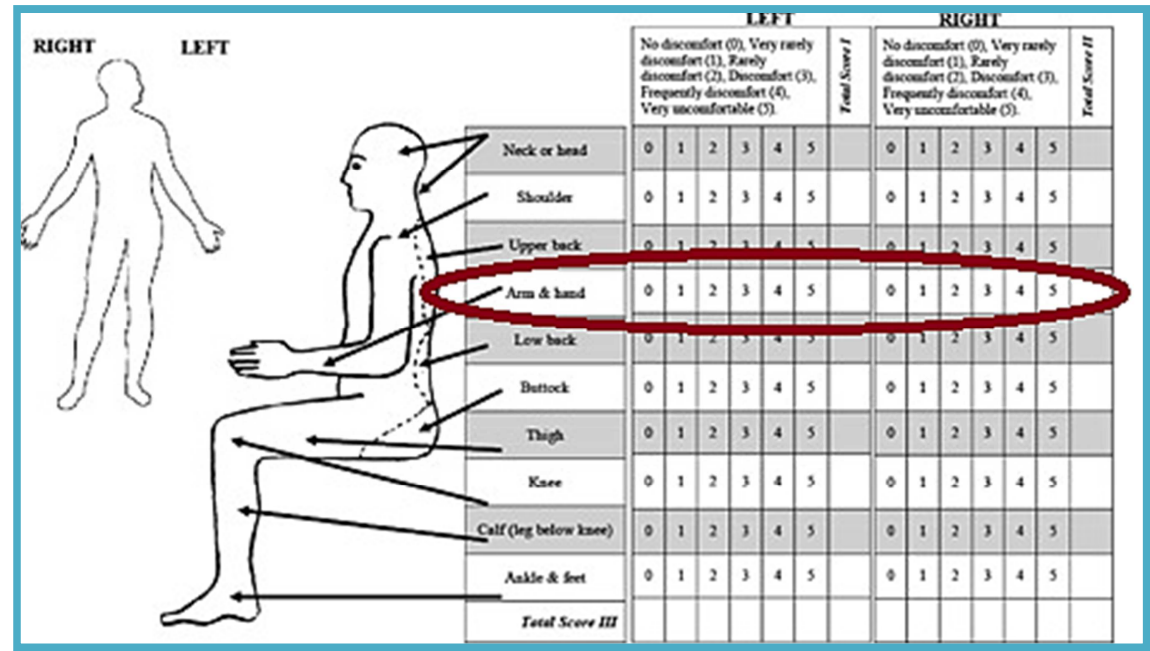

Figure 14. Body Discomfort Chart. 


\section{Appendix D. Common Paint Problems that Can Be Solved Using Scraper}

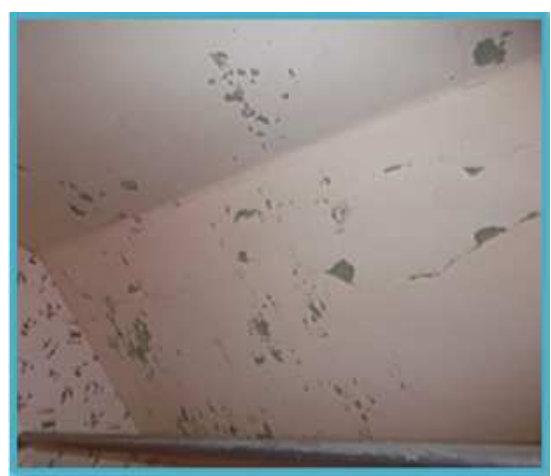

Figure 15. Crazing of Paint.

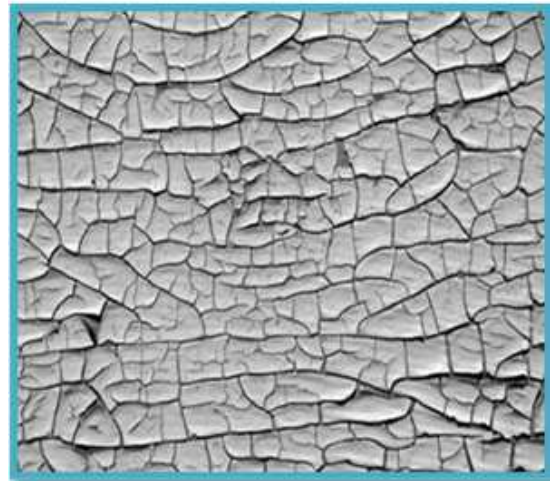

Figure 16. Peeling of Paint

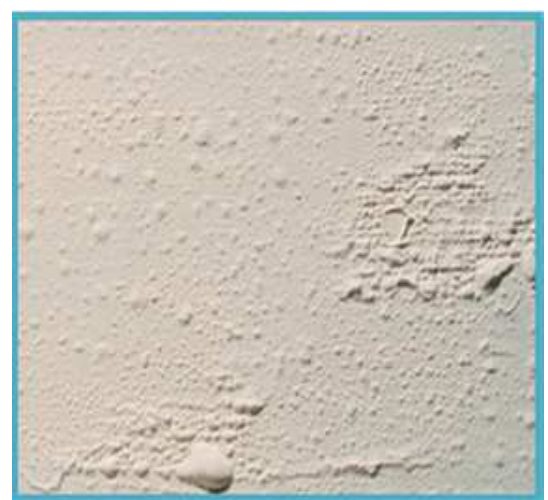

Figure 17. Solvent Blistering.

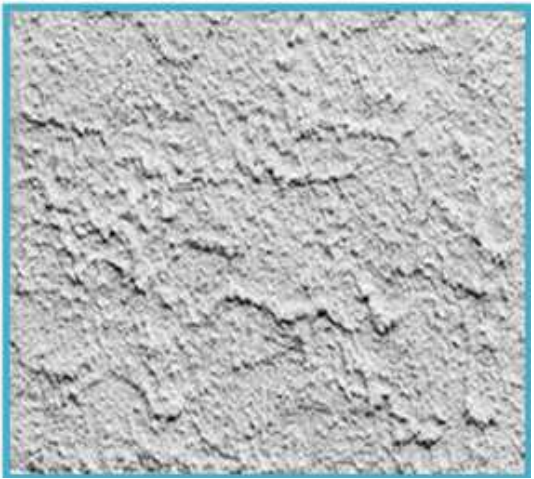

Figure 18. Wrinkling of Paint.

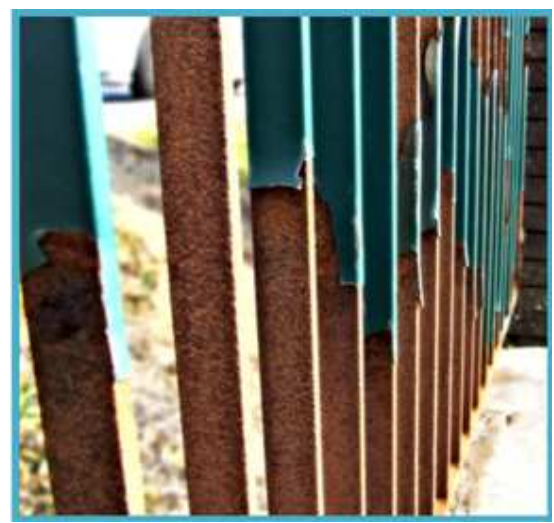

Figure 19. Flaking of Paint.

\section{Appendix E. Hypothesis Testing Results}

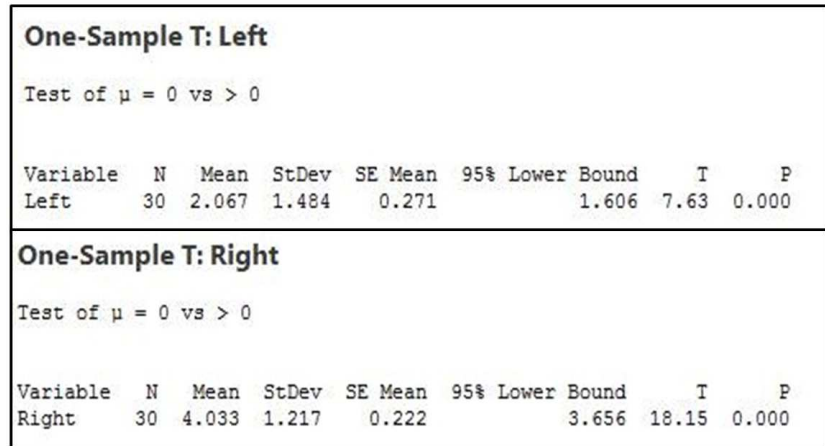

Figure 20. Minitab Results on Hypothesis Testing of Worker Discomfort.

\section{References}

[1] Allsteel, Inc. (2006). Ergonomics and Design A Reference Guide. Iowa: Muscatine.

[2] Administration, O. S. (2012, January). Injury and illness prevention programs. (United States Department of Labor) Retrieved August 4, 2019, from http://www.osha.gov/ dsg/InjuryIllnessPreventionProgramsWhitePaper.html

[3] Craven, J. (2019, July 3). ThoughtCo. Retrieved August 4, 2019, from https://www.thoughtco.com/how-to-removeexterior-paint-safely-3884401

[4] Stevens, K. (2018, September 12). Painting: choosing a paint scraper. (Networx) Retrieved August 4, 2019, from http://www.networx.com/article/painting-choosing-a-paintscraper

[5] Rouse, M. (2011, March). Cumulative trauma disorder (CTD). Retrieved November 12, 2017, from http://whatis.techtarget.com/definition/cumulative-traumadisorder-CTD

[6] BusinessWorld. (2018, 26 September). A construction boom and a thriving cement industry. Retrieved August 4, 2019 , from http://www.bworldonline.com/a-construction-boom-anda-thriving-cement-industry/

[7] Safety, C. C. (2019, April 8). Work-related musculoskeletal disorders (WMSDs). Retrieved August 4, 2019, from http://www.ccohs.ca/oshanswers/diseases/rmirsi.html 
[8] Cal/OSHA Consultation Service, R. a. (2007). Economic Guidelines for Manual Material Handling. Cincinnati: California Department of Industrial Relations.

[9] Work, E. A. (2019). Musculoskeletal disorders. (European Union - Occupational Safety and Health Agency) Retrieved August 4, 2019, from https://osha.europa.eu/topics/msds

[10] Goguen, D. (2017). Making a workers compensation claim for wrist tendonitis. Retrieved November 12, 2017, from http://www.alllaw.com/articles/nolo/workerscompensation/claim-wrist-tendonitis.html

[11] Brett Snider, E. (2014, October 29). Can you get workers' Ccmp for wrist injuries? Retrieved August 2019, 2019, from http://blogs.findlaw.com/injured/2014/10/can-you-getworkers-comp-for-wrist-injuries.html
[12] S. M., Q. (2013). Significance of Anthropometric Data for the Manufacturing Organizations. International Journal of Bioinformatics Research and Applications, 5 (I), 111-126.

[13] Boschman, J. S., Frings-Dresen, M. H., \& Van der Molen, H. F. (2014, December 29). Use of Ergonomic measures related to musculoskeletal complaints among construction workers: A 2-year follow-up study. Retrieved November 12, 2017.

[14] Aptel, M., Claudon, L., \& Marsot, J. (2002). Integration of Ergonomics into hand tool design: Principle and presentation of an example. International Journal of Occupational Safety and Ergonomics, 107-115. doi: $10.1080 / 10803548.2002 .11076518$

[15] Vink, P. (2008). Crucial Elements of Designing for Comfort. In Product Experience (pp. 441-460). Elsevier, Ltd. 